\title{
Intact and cleaved forms of the urokinase receptor enhance discrimination of cancer from non-malignant conditions in patients presenting with symptoms related to colorectal cancer
}

\author{
AF Lomholt ${ }^{*, I}$, G Høyer-Hansen ${ }^{2}$, HJ Nielsen' and IJ Christensen ${ }^{2}$ \\ 'Department of Surgical Gastroenterology, Copenhagen University Hospital Hvidovre, 30 Kettegaard Allé, DK-2650 Hvidovre, Denmark; ${ }^{2} T h e$ Finsen \\ Laboratory, Copenhagen Biocenter, 5 Ole Maaloes Vej, DK-2200 Copenhagen N, Denmark
}

BACKGROUND: Colorectal cancer (CRC) is a leading cause of cancer-related morbidity and mortality in developed countries. It is known that early detection results in improved survival, and consequently there is a need for improved diagnostic tools in CRC. The plasma level of soluble urokinase plasminogen activator receptor (suPAR) was proposed as a marker in CRC patients. This study was undertaken to evaluate the individual molecular forms of suPAR as discriminators in a group of patients undergoing endoscopical examination following symptoms related to colorectal cancer.

METHODS: In a case-control study comprising 308 patients undergoing endoscopical examination following CRC-related symptoms, 77 CRC patients with adenocarcinoma were age and gender matched to: 77 patients with adenomas; 77 with other non-malignant findings, and 77 with no findings. The different uPAR forms were measured in citrate plasma collected before endoscopical examination, using three different Time Resolved - Fluorescence Immuno Assays (TR-FIA's).

RESULTS: All soluble UPAR forms were found to be significantly higher in cancer patients than in patients presenting with other nonmalignant findings; uPAR(I) $P=0.0006$, suPAR $(I-I I I) P<0.000 I$ and suPAR $(I-I I I)+(I I-I I) P<0.000 I$, whereas no significant difference was found when performing similar comparisons for patients presenting with adenomas. The odds ratio (OR) for the comparison of UPAR(I) in patients with $\mathrm{CRC}$ to subjects with other non-malignant findings was 3.44 (95\% Cl:I.86-6.37). CRC patients had a mean elevated level of 20.9\% (95\% Cl:I0.2-32.6) for suPAR(I-III) and I8.5\% (95\% Cl:9.0-28.8) for suPAR $(I-I I I)+(I I-I I I)$ compared with subjects with non-malignant findings.

CONCLUSIONS: The findings confirm reports on increased UPAR expression in cancer patients and in particular elevated levels of suPAR in blood from CRC patients and indicate that suPAR levels in blood are increasing during carcinogenesis. Although none of the measured uPAR forms were cancer specific, our findings suggest that uPAR expression could be useful in the early detection of CRC when combined with other markers and clinical variables.

British Journal of Cancer (2009) I 0 I, 992-997. doi:I0.1038/sj.bjc.6605228 www.bjcancer.com

Published online I| August 2009

(C) 2009 Cancer Research UK

Keywords: UPAR; colorectal cancer; detection

Colorectal Cancer (CRC) is a leading cause of cancer with an estimated individual lifetime risk of $5 \%$ in developed countries. Worldwide CRC accounts for approximately 1 million new cases per year, and in Europe CRC is the second most prevalent cancer and the second most important in relation to cancerspecific death (Parkin et al, 2005; Ferlay et al, 2007). Outcome in CRC patients relates to the stage of disease at diagnosis, and because more than $50 \%$ of patients are diagnosed at a late stage of disease, there is a need for new diagnostic tools for early detection of CRC (Weitz et al, 2005). According to The World Health Organization conditions for early detection should be an appropriate disease-control approach: (1) concerning a common disease with serious morbidity and mortality; (2) potential

*Correspondence: Dr AF Lomholt; E-mail: annelomholt@hotmail.com Received I April 2009; revised 2 July 2009; accepted 9 July 2009; published online II August 2009 screening tests should be able to accurately detect early-stage disease; (3) treatment after detection should be proven to improve prognosis relative to usual diagnosis; and (4) evidence should exist that the potential benefits outweigh the potential harms and costs of screening (Winawer et al, 1990). In this respect CRC has been proposed as an ideal screening object, but so far no ideal screening method has been found. Presently the 'golden standard' for screening of patients at risk of CRC is colonoscopy, as the incidence of CRC in screening populations undergoing colonoscopy has been shown to decrease (Winawer et al, 1993; Levin et al, 2008). However, this procedure is time consuming, expensive, inconvenient for the patient and includes a small risk of perforation, and consequently colonoscopy is not ideal for primary population-based screening. The Faecal Occult Blood Test (FOBT) was proposed as a potential screening tool even though the sensitivity and specificity of this test were shown to vary considerably in different studies, additionally low compliance impose problems for the use of FOBT in CRC population-based 
screening (Hewitson et al, 2006; Burch et al, 2007). The search for molecular markers in blood has been promising and multiple markers have been proposed, but limited reproducibility results in bias emphasizing the need for studies designed for this purpose (Ransohoff, 2007). No serological marker has yet been accepted for use in early detection of CRC (Duffy et al, 2007), even though some serological biomarkers, among these the urokinase receptor, uPAR, have proven to be strong prognostic markers in CRC (Stephens et al, 1999).

The plasminogen activation system (PA-system) is involved in tissue remodelling processes, including tumour invasion and metastasis (Werb, 1997; Irigoyen et al, 1999; Andreasen et al, 2000). Components of this system including the urokinase plasminogen activator (uPA), its receptor UPAR and the UPA inhibitor (PAI-1), have been shown to be elevated in tumour tissue and blood from cancer patients including patients with CRC (Ganesh et al, 1994, 1996; Pedersen et al, 1994; Stephens et al, 1999; Mustjoki et al, 2000; Riisbro et al, 2002; Hoyer-Hansen and Lund, 2007).

UPAR has a central function, because binding of the zymogen pro-uPA initiates activation of cell surface bound plasminogen leading to other proteolytic events in the extracellular matrix (Ellis et al, 1989). UPAR(I-III) consists of three domains denoted uPAR(I), uPAR(II) and uPAR(III) connected by two linker regions, and the crystal structure has been solved (Llinas et al, 2005). uPAR(III) is attached to cell membrane by a glycosyl-phosphatidyl-inositol (GPI) anchor(Ploug et al, 1991). Intact uPAR is required for efficient binding of uPA (Hoyer-Hansen et al, 1997). uPAR(I-III) can also be cleaved in the linker region between domains I and II by uPA, liberating uPAR(I) and leaving the cleaved form, uPAR(II-III) on the cell surface (Hoyer-Hansen et al, 1992). UPA has been shown to cleave uPAR in vivo (Zhou et al, 2000). uPAR is shed from the cell surface and soluble forms of UPAR: suPAR(I-III), suPAR(II-III) and UPAR(I) have been detected in various body fluids (Hoyer-Hansen and Lund, 2007). Although the mechanism of uPAR shedding is not clarified, evidence has been provided that the glycolipid (GPI) anchor can be cleaved by endogenous cellular GPI-specific phospholipase D (GPI-PLD) (Wilhelm et al, 1999). Although GPI-anchored uPAR(I-III) is readily cleaved by uPA, suPAR(I-III) cannot be cleaved by uPA in the linker region between domains I and II (Hoyer-Hansen et al, 2001; Hoyer-Hansen and Lund, 2007). Thus, uPAR(I) detected in blood results from cell surface cleavage of uPAR(I-III) and suPAR(II-III) is in addition shed from the cell surface.

In colon cancer uPAR is expressed by tumour-infiltrating macrophages and fibroblasts and by a few cancer cells (Pyke et al, 1994; Ohtani et al, 1995). Total levels of all uPAR forms in tumour extracts and as before mentioned in blood have been shown to correlate with poor prognosis in patients with colorectal cancer (Ganesh et al, 1994; Stephens et al, 1999; Konno et al, 2001). We hypothesized that cleavage of UPAR is an indication of an active plasminogen activation system and that the amounts of the individual cleavage products would consequently be superior to the total uPAR level as diagnostic markers of cancer. To investigate this we employed immunoassays selectively quantifying the individual UPAR forms (Piironen et al, 2004). Using these assays we have previously shown that the serum level of uPAR(I) enhances the discrimination of benign from malignant prostatic disease (Piironen et al, 2006). In addition, uPAR(I) was found to be a stronger prognostic marker than the total amount of UPAR in non-small cell lung cancer (Almasi et al, 2005). In a recent study, we also showed that $\operatorname{suPAR}(\mathrm{I})$ in blood enhances discrimination of benign from malignant disease and uPAR(I) in blood predicts survival in patients with ovarian cancer (Henic et al, 2008).

This case-control study was undertaken to evaluate the potential discriminatory value of the plasma uPAR variants in four diagnostic groups of patients undergoing endoscopical examination following symptoms related to CRC.

\section{SUBJECTS AND METHODS}

\section{Subjects}

From October 2003 through December 2005, subjects were included in a multi-centre cross sectional study conducted at six Danish hospitals. Eligible for inclusion were patients (aged $18+$ years) undergoing endoscopical examination following symptoms related to CRC and patients attending surveillance programs due to Hereditary Colorectal Cancer (HNPCC and FAP). Subjects previously diagnosed with CRC and subjects unable to give informed consent were excluded from the study. The Regional Ethical Committee approved the study. Following oral and written consent according to the Helsinki II Declaration, 5165 individuals were included consecutively - for details see (Nielsen et al, 2007). Based on this study population a case-control study was designed including 312 patients representing four diagnostic groups of subjects. This study population was selected to test the diagnostic potential of different promising serological markers in CRC. Primarily, 78 subjects with pathologically verified colorectal adenocarcinomas (25\% RC, $n=20$ and $75 \%$ CC, $n=58)$ were selected at random. For each of these, a subject with pathologically verified adenomatous changes was randomly selected matching for age, gender and localisation of finding. Then subjects with other (non-malignant) findings were randomly selected and matched as described for the adenomas, and finally subjects were randomly selected who had no findings at endoscopy and who reported no co-morbidity. All pathological diagnoses were validated using the Danish National Registry on Pathological Examinations (www. patobank.dk). Patients who were diagnosed with cancer but did not have the tumour removed were classified according to the clinical information available, and as a result exact tumour staging was not possible in all cases. Similarly for patients diagnosed with adenomas, the type of adenoma was not specified in all cases, either because of incompleteness of the pathological description available or due to loss for specimen during the examination. Previous cancer diagnoses were retrieved from the Danish Cancer Registry, one subject had a previous CRC and was excluded from the study together with three matched subjects, leaving a study population of 308 subjects. Descriptive statistics for the matched subjects are given in Table 1.

\section{Sampling}

Blood samples were collected before endoscopical examination in all subjects, following a standard operating procedure (Nielsen et al, 2007).

At sample collection subjects were non-fasting. Patients undergoing colonoscopy had completed a bowel preparation. Blood was collected at moderate tourniquet pressure; in $4 \mathrm{ml}$ citrate-coated tubes (Vacutainer Becton-Dickinson, Mountain View, CA, USA), and spun for $10 \mathrm{~min}$ at $2500 \mathrm{~g}$ and $4{ }^{\circ} \mathrm{C}$ within $1 \mathrm{~h}$ following collection. Plasma was collected and samples were immediately stored at $-80^{\circ} \mathrm{C}$ and were thawed and refrozen once before analysis.

\section{Immunoassay}

Samples were analysed using three different Time Resolved Fluorescence Immuno Assays (TR-FIAs). TR-FIA 1 measuring full-length suPAR(I-III), TR-FIA 2 measuring full-length and cleaved suPAR(I-III) + (II-III), and TR-FIA 3 measuring liberated domain I, uPAR(I). All samples were analysed in a 1:5 dilution. The assays and their validation in citrate plasma have previously been described (Henic et al, 2008). In all three settings samples were read in the Floustar Galaxy fluorometer with excitation set at $405 \mathrm{~nm}$ and emission read at $615 \mathrm{~nm}$ with a $400 \mu$ s delay and a $400 \mu$ s acquisition window. 
Table I Subject characteristics for each case/controls with 77 individuals in each group

\begin{tabular}{|c|c|}
\hline & Subjects, $n(\%)$ \\
\hline \multicolumn{2}{|l|}{ Gender } \\
\hline Female & $37(48)$ \\
\hline Male & $40(52)$ \\
\hline \multicolumn{2}{|l|}{ Age group } \\
\hline $40+$ & $3(4)$ \\
\hline $50+$ & $10(13)$ \\
\hline $60+$ & $17(22)$ \\
\hline $70+$ & $26(34)$ \\
\hline $80+$ & $21(27)$ \\
\hline \multicolumn{2}{|l|}{ Localisation } \\
\hline Right colon & $23(30)$ \\
\hline Left colon & $34(44)$ \\
\hline Rectum & $20(26)$ \\
\hline \multicolumn{2}{|l|}{ Cancer stage } \\
\hline 1 & $9(12)$ \\
\hline$\|$ & $32(42)$ \\
\hline III & $16(21)$ \\
\hline IV & $15(19)$ \\
\hline not specified & $5(6)$ \\
\hline \multicolumn{2}{|l|}{ Adenomas } \\
\hline Tubular & $45(58)$ \\
\hline Tubulovillous & $16(21)$ \\
\hline Villous & I (I) \\
\hline Serrat & I (I) \\
\hline Not specified & $14(18)$ \\
\hline \multicolumn{2}{|l|}{ Size } \\
\hline$<\mathrm{l} \mathrm{cm}$ & $41(53)$ \\
\hline$>1 \mathrm{~cm}$ & $33(43)$ \\
\hline Not specified & $3(4)$ \\
\hline \multicolumn{2}{|l|}{ Other non-malignant finding } \\
\hline Diverticulosis & $72(94)$ \\
\hline Haemorrhoids & $4(5)$ \\
\hline Inflammatory bowel disease & $1(1)$ \\
\hline
\end{tabular}

\section{Statistics}

Descriptive statistics are presented by the median, minimum, maximum or frequency if applicable. The Spearman's rank correlation was used as a measure of association. The statistical analyses were based on a case-control design. For suPAR(I-III) and suPAR(I-III) + (II-III) a normal distribution was assumed following log-transformation (natural). Domain I (uPAR(I)) was treated as a binary variable using the limit of quantification of the assay as the cut-point. Primarily a test for association between the serological marker and CRC, adenoma, ONM findings and no findings (hereafter denoted diagnosis groups) was carried out. The analysis was done using a general linear model with diagnosis group as the explanatory variable and the serological marker as the dependent variable. For markers normally distributed on the log scale, the link function used was the identity function and for dichotomized serological markers, the logit was chosen as the link function. The analysis used repeated measures with subject being each case with corresponding samples. For each case, the proportion of cancer patients with uPAR levels exceeding the level found in the corresponding adenoma, ONM and no finding was estimated with $95 \%$ CI.

Database management and statistical calculations were done using SAS (v 9.1, SAS Institute, Cary, NC, USA). $P$-values below $5 \%$ were considered significant.

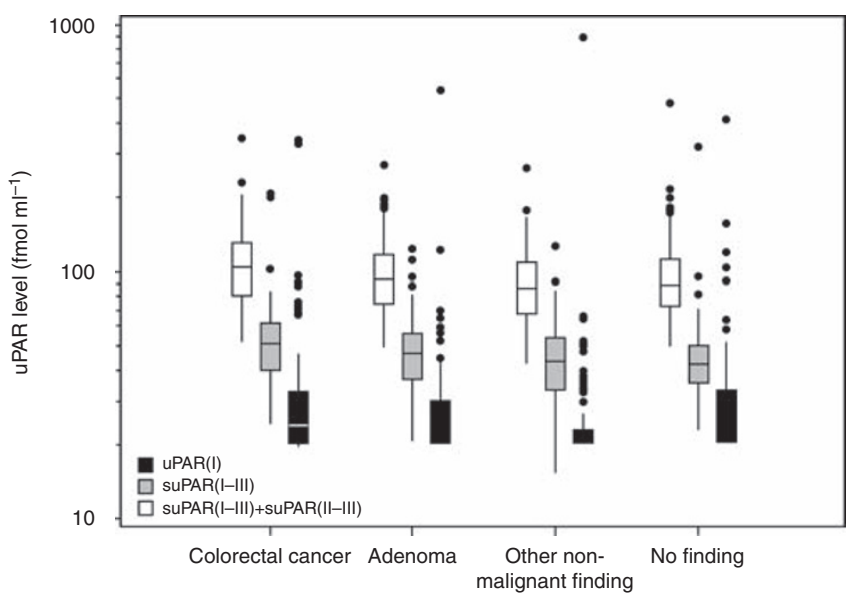

Figure I Box plot showing the distribution of the different plasma uPAR forms in the four different diagnostic groups.

Table 2 uPAR $(I)$ treated as a binary variable with cut-point at the limit of quantification or the $3 r d$ quartile

\begin{tabular}{lcc}
\hline Diagnostic group & $\begin{array}{c}\text { Limit of quantification + } \\
\text { uPAR(I), } \boldsymbol{n}(\%)\end{array}$ & $\begin{array}{c}\text { > 3rd quartile + } \\
\text { uPAR(I), } \boldsymbol{n}(\%)\end{array}$ \\
\hline CRC & $46(59.7)$ & $25(32.5)$ \\
Adenoma & $36(46.8)$ & $18(23.4)$ \\
Other non- & $28(36.4)$ & $12(15.6)$ \\
malignant finding & $38(49.4)$ & $22(28.6)$ \\
No finding &
\end{tabular}

The table shows the proportion of subjects with detectable UPAR $(I)$ in each diagnosis group $(n=77)$.

\section{RESULTS}

Patient characteristics for the 77 matched subjects including age; gender and localization of findings are given in Table 1. In Figure 1 plasma levels of the different UPAR forms are depicted for each diagnostic group. All soluble uPAR forms were found to be significantly higher in cancer patients than in patients presenting with ONM findings; uPAR(I) $P=0.0006$, suPAR(I-III) $P<0.0001$ and suPAR(I-III) + (II-III) $P<0.0001$. Comparisons between the group of patients presenting with adenomas and the remaining diagnostic groups showed no significant difference.

\section{Association between the different suPAR variants}

To evaluate the association between the different suPAR variants the Spearman's rank coefficient was calculated. In all cases a significant correlation between the different suPAR variants was shown $\mathrm{p}<0.0001$ (data not shown). The weakest correlation was found comparing uPAR(I) and suPAR(I-III) resulting in a 0.60 correlation coefficient $(P<0.0001)$.

\section{Discriminatory value of the different UPAR variants}

Domain I; $u P A R(I) \quad$ UPAR(I) was treated as a binary variable with the limit of quantification $\left(\mathrm{LOQ}=20.19 \mathrm{fmol} \mathrm{ml}^{-1}\right.$ ) as the cutpoint. The resulting discrimination is shown in Table 2. Performing a general evaluation of the differences between the different groups (type 3 hypothesis) a significant difference was found $(P=0.008)$. A repeated measures analysis shows that in the cancer group there are significantly more cases with uPAR(I) levels above the quantification limit than in the group with ONM findings 
Table 3 The odds ratios (OR) for elevated uPAR(I) comparing diagnostic groups.(ONM = other non-malignant)

\begin{tabular}{lcr}
\hline Groups & $\begin{array}{c}\text { Odds ratio and } \\
\text { (95\% confidence limits) }\end{array}$ & $\boldsymbol{P}$-value \\
\hline ONM finding vs no finding & $0.50(0.25-0.99)$ & 0.047 \\
Adenoma vs no finding & $1.18(0.62-2.23)$ & 0.611 \\
Adenoma vs ONM finding & $2.38(1.27-4.47)$ & 0.007 \\
CRC vs adenoma & $1.45(0.79-2.63)$ & 0.235 \\
CRC vs no finding & $1.71(0.91-3.18)$ & 0.093 \\
CRC vs ONM finding & $3.44(1.86-6.37)$ & $<0.0001$ \\
\hline
\end{tabular}

Table 4 Relative mean difference (\%) between the diagnostic groups for intact suPAR and intact+cleaved suPAR

\begin{tabular}{|c|c|c|c|}
\hline Marker & Groups & $\begin{array}{l}\text { Relative mean } \\
\text { difference and } \\
(95 \% \text { confidence } \\
\text { limits in } \%)\end{array}$ & $P$-value \\
\hline $\operatorname{suPAR}(|-|||)$ & Non-malignant vs No & $-3.3(-13.3-5.8)$ & 0.488 \\
\hline \multirow{5}{*}{$P=0.002^{\mathrm{a}}$} & Adenoma vs no finding & $6.4(-3.4-17.2)$ & 0.208 \\
\hline & Adenoma vs ONM finding & $9.9(-0.1-21.0)$ & 0.052 \\
\hline & CRC vs adenoma & $9.0(-1.5-18.5)$ & 0.089 \\
\hline & CRC vs no finding & $17.0(5.5-29.7)$ & 0.003 \\
\hline & CRC vs ONM finding & $20.9(10.2-32.6)$ & $<0.0001$ \\
\hline $\operatorname{suPAR}(|-| \| \mid)+(\|-|\||)$ & Non-malignant vs No & $-6.5(-17.0-3.1)$ & 0.190 \\
\hline \multirow[t]{5}{*}{$P=0.004^{\mathrm{a}}$} & Adenoma vs no finding & $2.3(-7.2-12.7)$ & 0.653 \\
\hline & Adenoma vs ONM finding & $8.9(-0.8-19.5)$ & 0.072 \\
\hline & CRC vs adenoma & $8.1(-1.9-17.2)$ & 0.110 \\
\hline & CRC vs no finding & $11.3(-0.1-24.0)$ & 0.052 \\
\hline & CRC vs ONM finding & $18.5(9.0-28.8)$ & $<0.0001$ \\
\hline
\end{tabular}

${ }^{a}$ Results of type III hypothesis tests (ONM = other non-malignant).

$(P=0.009)$, whereas all other comparisons are non-significant. Dichotomizing the data at the $3 \mathrm{rd}$ quartile $\left(31.23 \mathrm{fmol} \mathrm{ml}^{-1}\right)$ did not result in an improved discrimination (Table 2). Odds ratios were calculated to evaluate the probability of uPAR(I) being elevated in one diagnostic group compared with another. Significant ORs were found when comparing the ONM finding group to the CRC group (Table 3 ).

$\operatorname{suPAR}(I-I I I)$ Intact suPAR (suPAR(I-III)) was treated as a continuous variable on the log scale, and the discriminatory value was evaluated comparing mean levels for the different diagnostic groups given as the relative difference (Table 4$)$. The type 3 -hypothesis test was significant $(P=0.002)$. When comparing the CRC group to ONM and 'no findings' group's significant relative differences in mean suPAR(I-III) levels were found $(20.9 \%$ (95\% CI:10.2-32.6), $P<0.0001$ and $17.0 \%$ (95\% CI:5.5-29.7), $P=0.003$, respectively). Comparison of the adenoma and ONM finding groups showed a relative difference of $9.9 \%$ ((95\% CI: $0.1-$ $21.0), P=0.052$ ) All other comparisons were insignificant. Pooling the non-CRC groups and testing for a difference between CRC and this group showed a significant difference $(P=0.002)$.

suPAR(I-III) + (II-III) Intact and cleaved suPAR (suPAR(I$\mathrm{III})+(\mathrm{II}-\mathrm{III})$ ) was treated as a continuous variable on the log scale, and the discriminatory value was evaluated comparing mean levels for the different diagnostic groups (Table 4). The type 3 hypothesis was significant $(P=0.004)$. For suPAR(I-III $)+($ II - III $)$ a significant difference was found comparing suPAR(I-III) + (II-III) levels in the CRC group to the levels in the ONM finding group $(18.5 \% \quad(95 \%$ CI:9.0-28.8), $P<0.0001)$. The relative difference between the CRC patients and subjects with no findings
Table 5 Showing the proportion of cancer patients with UPAR levels exceeding the level found in the corresponding adenoma, ONM and no finding was estimated with $95 \% \mathrm{Cl}$

\begin{tabular}{|c|c|c|c|c|}
\hline & Subset & $\begin{array}{c}\text { Adenoma } \\
(95 \% \mathrm{Cl})\end{array}$ & $\begin{array}{l}\text { Other } \\
(95 \% \mathrm{Cl})\end{array}$ & $\begin{array}{c}\text { None } \\
(95 \% \mathrm{Cl})\end{array}$ \\
\hline $\operatorname{suPAR}(|-|||)+(||-|| \mid)$ & $\begin{array}{l}\text { All } \\
\text { MO }\end{array}$ & $\begin{array}{l}64(53-74) \\
59(44-73)\end{array}$ & $\begin{array}{l}70(60-80) \\
67(54-80)\end{array}$ & $\begin{array}{l}66(56-77) \\
61(48-75)\end{array}$ \\
\hline suPAR(I-III) & $\begin{array}{l}\text { All } \\
\text { MO }\end{array}$ & $\begin{array}{l}55(43-66) \\
51(37-65)\end{array}$ & $\begin{array}{l}70(60-80) \\
67(54-80)\end{array}$ & $\begin{array}{l}64(53-74) \\
61(48-75)\end{array}$ \\
\hline $\operatorname{uPAR}(I)^{\mathrm{a}}$ & $\begin{array}{l}\text { All } \\
\text { MO }\end{array}$ & $\begin{array}{l}61(49-73) \\
54(38-70)\end{array}$ & $\begin{array}{l}67(55-80) \\
68(49-83)\end{array}$ & $\begin{array}{l}60(48-72) \\
59(44-75)\end{array}$ \\
\hline
\end{tabular}

$\mathrm{MO}=$ analyses restricted to the group of patients presenting no distant metastases $(n=49) .{ }^{\text {aTies }}$ excluded

was $11.3 \%(95 \% \mathrm{CI}: 0.1-24.0, \quad P=0.052)$, for subjects with adenomas compared to those with ONM finding the difference was $8.9 \%$ (95\% CI: $0.8-19.5, P=0.072)$. All other comparisons were insignificant. Pooling the groups presenting no CRC and testing for a difference between the CRC group and this group showed a significant difference $(P=0.007)$.

Proportional analyses of all UPAR variants The proportion of patients presenting higher uPAR values than patients in the other diagnosis groups was analysed for each case, and for the M0 ( = no distant metastasis diagnosed) CRC patients, respectively. Results are given in Table 5 .

\section{DISCUSSION}

In this case-control study, plasma levels of the different uPAR variants were shown to increase with severity of each diagnostic group. For all three markers significant higher levels were seen in the CRC group compared with the uPAR levels in the other three diagnostic groups, suggesting that the markers used in this study may be potential discriminators in the early detection of colorectal cancer. Even though none of the markers were cancer specific the suPAR variants should not be excluded as potential tools in the detection and classification of CRC patients. Previous studies have shown diagnostic value of uPAR variants when combined with other serological markers in both ovarian and prostate cancer (Piironen et al, 2006; Henic et al, 2008).

In this study the number of patients with detectable levels of uPAR(I) was shown to be significantly lower in the diagnostic group 'ONM findings' compared with the CRC and adenoma groups. For the levels of suPAR(I-III) + (II-III) significant differences were only seen when comparing the groups CRC and 'ONM findings'. Therefore uPAR(I), when compared with other soluble UPAR forms, may be superior as a diagnostic marker in CRC. When this was analysed by a proportional analysis of each case compared with matched patients from the other diagnosis groups (Table 5), uPAR(I) were not superior to the two other uPAR variants studied. However, there are strong indications that the blood level of uPAR(I) reflects the activity of uPA (Zhou et al, 2000). Thus high levels are indicative of high uPA activity, leading to plasmin formation and breakdown of the extracellular matrix, which is a prerequisite for cancer invasion (Dano et al, 2005). Notably levels of uPAR(I) have previously been shown to be of interest both in cancer detection and as a prognostic marker (Almasi et al, 2005; Piironen et al, 2006; Henic et al, 2008).

In all analyses of the different UPAR forms, the CRC group presented significantly higher values than the remaining groups. This observation supports the hypothesis that suPAR levels in blood are increasing during carcinogenesis (Piironen et al, 2006; Henic et al, 2008) and despite the insignificant differences between 
the adenoma group and 'ONM/no findings' groups the hypothesis was supported by a 'trend' going towards the level of significance when comparing these groups (see Table 4). As shown in Table 1 all diagnoses in the adenoma group could not be certified pathologically, a fact that may bias our findings. In addition, it is well established that some adenomas have higher risk of transforming into carcinomas than others (Bond, 2003). Owing to data limitations differences in UPAR levels were not studied according to adenoma type or size, variables that are indeed of great interest when studying potential screening markers in CRC.

For all markers the most significant differences between groups were found when comparing the diagnostic groups: CRC and 'ONM finding'. Initially the group of 'no finding', characterized by having no reported co-morbidity and no findings at endoscopical examination, were expected to present with the lowest levels of the different uPAR forms and hence the most significant differences compared with CRC. When interpreting the results of this study, it should be noted that all included subjects were symptomatic and when looking at the actual mean values for the two groups: no findings and 'ONM' findings they were only slightly different $-3.3 \%$ for suPAR (I-III) and $-6.5 \%$ for suPAR (I-III) + (II-III). The diagnostic group of 'ONM finding' appeared to be very homogeneous and - with one exception - only included subjects presenting benign lesions of the bowel wall (diverticulosis and haemorrhoids). suPAR has been reported to be elevated in different cancers, but whether suPAR is elevated in other systemic diseases is not well described. Total suPAR has been shown to be elevated in patients with infectious and inflammatory diseases; hence suPAR levels may be elevated because of co-morbidity. Patients could have systemic disease at the time of the examination that were not registered and hence present increased levels of UPAR.

All soluble uPAR forms were shown to be markers of interest in the detection of CRC despite the fact that they were not cancer

\section{REFERENCES}

Almasi CE, Hoyer-Hansen G, Christensen IJ, Dano K, Pappot H (2005) Prognostic impact of liberated domain I of the urokinase plasminogen activator receptor in squamous cell lung cancer tissue. Lung Cancer 48: $349-355$

Andreasen PA, Egelund R, Petersen HH (2000) The plasminogen activation system in tumor growth, invasion, and metastasis. Cell Mol Life Sci 57: $25-40$

Bond JH (2003) Colon polyps and cancer. Endoscopy 35: 27-35

Burch JA, Soares-Weiser K, St John DJ, Duffy S, Smith S, Kleijnen J, Westwood M (2007) Diagnostic accuracy of faecal occult blood tests used in screening for colorectal cancer: a systematic review. J Med Screen 14: $132-137$

Dano K, Behrendt N, Hoyer-Hansen G, Johnsen M, Lund LR, Ploug M, Romer J (2005) Plasminogen activation and cancer. Thromb Haemost 93: $676-681$

Duffy MJ, van DA, Haglund C, Hansson L, Holinski-Feder E, Klapdor R, Lamerz R, Peltomaki P, Sturgeon C, Topolcan O (2007) Tumour markers in colorectal cancer: European Group on Tumour Markers (EGTM) guidelines for clinical use. Eur J Cancer 43: 1348-1360

Ellis V, Scully MF, Kakkar VV (1989) Plasminogen activation initiated by single-chain urokinase-type plasminogen activator. Potentiation by U937 monocytes. J Biol Chem 264: 2185-2188

Ferlay J, Autier P, Boniol M, Heanue M, Colombet M, Boyle P (2007) Estimates of the cancer incidence and mortality in Europe in 2006. Ann Oncol 18: $581-592$

Ganesh S, Sier CF, Heerding MM, van Krieken JH, Griffioen G, Welvaart K, van d V, Verheijen JH, Lamers CB, Verspaget HW (1996) Prognostic value of the plasminogen activation system in patients with gastric carcinoma. Cancer 77: 1035-1043

Ganesh SJ, Sier C, Heerding M, Griffioen G, Lamers C, Verspaget H (1994) Urokinase receptor and colorectal cancer survival. The Lancet 344: $401-402$

Henic E, Borgfeldt C, Christensen IJ, Casslen B, Hoyer-Hansen G (2008) Cleaved forms of the urokinase plasminogen activator receptor in plasma specific. These findings lead to the hypothesis that including these markers in a multi-marker profile could be beneficial in the detection and classification of CRC when combined with other markers and clinical variables, as previously shown in prostate and ovarian cancer.

A sufficiently powered study including other variables that may influence the uPAR levels (co-morbidity, life style variables) could be conducted measuring uPAR levels in the original study population of more than 5000 individuals. This would allow for an evaluation of the possibility of identifying individuals with a high risk for CRC adjusted for relevant clinical variables and to evaluate UPAR levels in association with other serological biomarkers such as carcinoembryonic antigen and plasma tissue inhibitor of metalloproteinases-1 (Nielsen et al, 2007).

\section{ACKNOWLEDGEMENTS}

The excellent technical assistance of Ruth Petersson is gratefully acknowledged. The Danish-Australian Endoscopy Study Group on Colorectal Cancer Detection is thanked for providing the samples and clinical data. The study was supported by: EU contract LSHC-CT-2003-503297, The Kornerup Fund, The Aase and Ejnar Danielsen Fund, The Aage and Johanne Louis-Hansen Fund, The Walter and O. Kristiane Christensen Fund, The Sophus and Astrid Jacobsen Fund, The Arvid Nilsson Fund, The Glunz and Jensen Fund, The Friedrich and Else Boehm Fund, The Agnes and Poul Friis Fund, The Eva and Henry Fraenkel Fund, The Hartmann Bros. Fund, The Willy and Ingeborg Reinhard Fund, The Katrine and Vigo Skovgaard Fund, The Oda and Hans Svenningsen Fund, The Einar Willumsen Fund, and The Danish Cancer Society (Hans Jørgen Nielsen is Danish Cancer Society Professor of Surgical Oncology).

have diagnostic potential and predict postoperative survival in patients with ovarian cancer. Clin Cancer Res 14: 5785-5793

Hewitson P, Glasziou P, Irwig L, Towler B, Watson E (2006) Screening for colorectal cancer using the faecal occult blood test, Hemoccult. Cochrane Database Syst Rev, Issue 4: Art. No: CD001216

Hoyer-Hansen G, Behrendt N, Ploug M, Dano K, Preissner KT (1997) The intact urokinase receptor is required for efficient vitronectin binding: receptor cleavage prevents ligand interaction. FEBS Lett 420: 79-85

Hoyer-Hansen G, Lund IK (2007) Urokinase receptor variants in tissue and body fluids. Adv Clin Chem 44: 65-102

Hoyer-Hansen G, Pessara U, Holm A, Pass J, Weidle U, Dano K, Behrendt N (2001) Urokinase-catalysed cleavage of the urokinase receptor requires an intact glycolipid anchor. Biochem J 358: 673-679

Hoyer-Hansen G, Ronne E, Solberg H, Behrendt N, Ploug M, Lund LR, Ellis V, Dano K (1992) Urokinase plasminogen activator cleaves its cell surface receptor releasing the ligand-binding domain. J Biol Chem 267: $18224-18229$

Irigoyen JP, Munoz-Canoves P, Montero L, Koziczak M, Nagamine Y (1999) The plasminogen activator system: biology and regulation. Cell Mol Life Sci 56: $104-132$

Konno H, Abe J, Kaneko T, Baba M, Shoji A, Sunayama K, Kamiya K, Tanaka T, Suzuki S, Nakamura S, Urano T (2001) Urokinase receptor and vascular endothelial growth factor are synergistically associated with the liver metastasis of colorectal cancer. Jpn J Cancer Res 92: 516-523

Levin B, Lieberman DA, McFarland B, Smith RA, Brooks D, Andrews KS, Dash C, Giardiello FM, Glick S, Levin TR, Pickhardt P, Rex DK, Thorson A, Winawer SJ, for the American Cancer Society Colorectal Cancer Advisory Group tUM-STFatACoRCCC (2008) Screening and Surveillance for the Early Detection of Colorectal Cancer and Adenomatous Polyps, 2008: A Joint Guideline from the American Cancer Society, the US Multi-Society Task Force on Colorectal Cancer, and the American College of Radiology. CA Cancer J Clin 58: 130-160

Llinas P, Le Du MH, Gardsvoll H, Dano K, Ploug M, Gilquin B, Stura EA, Menez A (2005) Crystal structure of the human urokinase plasminogen 
activator receptor bound to an antagonist peptide. $E M B O J$ 24: $1655-1663$

Mustjoki S, Sidenius N, Sier CFM, Blasi F, Elonen E, Alitalo R, Vaheri A (2000) Soluble urokinase receptor levels correlate with number of circulating tumor cells in acute myeloid leukemia and decrease rapidly during chemotherapy. Cancer Res 60: 7126-7132

Nielsen HJ, Brunner N, Frederiksen CB, Lomholt AF, King D, Jørgensen LN, Olsen J, Rahr HB, Thygesen K, Hoyer U, Laurgberg S, Christensen IJ (2007) Plasma tissue inhibitor of metalloproteinases-1(TIMP-1): A novel biological marker in the detection of primary colorectal cancer. Protocol outlines of the Danish-Australian endoscopy study group on colorectal cancer detection. Scand J Gastroenterol 43(2): 242-248

Ohtani H, Pyke C, Dano K, Nagura H (1995) Expression of urokinase receptor in various stromal-cell populations in human colon cancer: immunoelectron microscopical analysis. Int J Cancer 62: 691-696

Parkin DM, Bray F, Ferlay J, Pisani P (2005) Global Cancer Statistics, 2002. CA Cancer J Clin 55: 74-108

Pedersen H, Brunner N, Francis D, Osterlind K, Ronne E, Hansen HH, Dano K, Grondahl-Hansen J (1994) Prognostic impact of urokinase, urokinase receptor, and type 1 plasminogen activator inhibitor in squamous and large cell lung cancer tissue. Cancer Res 54: 4671-4675

Piironen T, Haese A, Huland H, Steuber T, Christensen IJ, Brunner N, Dano K, Hoyer-Hansen G, Lilja H (2006) Enhanced discrimination of benign from malignant prostatic disease by selective measurements of cleaved forms of urokinase receptor in serum. Clin Chem 52: 838-844

Piironen T, Laursen B, Pass J, List K, Gardsvoll H, Ploug M, Dano K, HoyerHansen G (2004) Specific immunoassays for detection of intact and cleaved forms of the urokinase receptor. Clin Chem 50: 2059-2068

Ploug M, Behrendt N, Lober D, Dano K (1991) Protein structure and membrane anchorage of the cellular receptor for urokinase-type plasminogen activator. Semin Thromb Hemost 17: 183-193

Pyke C, Ralfkiaer E, Ronne E, Hoyer-Hansen G, Kirkeby L, Dano K (1994) Immunohistochemical detection of the receptor for urokinase plasminogen activator in human colon cancer. Histopathology 24: $131-138$

Ransohoff DF (2007) How to improve reliability and efficiency of research about molecular markers: roles of phases, guidelines, and study design. J Clin Epidemiol 60: 1205-1219

Riisbro R, Christensen IJ, Piironen T, Greenall M, Larsen B, Stephens RW, Han C, Hoyer-Hansen G, Smith K, Brunner N, Harris AL (2002) Prognostic significance of soluble urokinase plasminogen activator receptor in serum and cytosol of tumor tissue from patients with primary breast cancer. Clin Cancer Res 8: 1132-1141

Stephens RW, Nielsen HJ, Christensen IJ, Thorlacius-Ussing O, Sorensen S, Dano K, Brunner N (1999) Plasma urokinase receptor levels in patients with colorectal cancer: relationship to Prognosis. J Natl Cancer Inst 91: $869-874$

Weitz J, Koch M, Debus J, Hohler T, Galle PR, Buchler MW (2005) Colorectal cancer. Lancet 365: $153-165$

Werb Z (1997) ECM and cell surface proteolysis: regulating cellular ecology. Cell 91: $439-442$

Wilhelm OG, Wilhelm S, Escott GM, Lutz V, Magdolen V, Schmitt M, Rifkin DB, Wilson EL, Graeff H, Brunner G (1999) Cellular glycosylphosphatidylinositol-specific phospholipase D regulates urokinase receptor shedding and cell surface expression. J Cell Physiol 180: 225-235

Winawer SJ, St JJ, Bond J, Hardcastle JD, Kronborg O, Flehinger B, Schottenfeld D, Blinov NN (1990) Screening of average-risk individuals for colorectal cancer. WHO collaborating centre for the prevention of colorectal cancer. Bull World Health Organ 68: 505-513

Winawer SJ, Zauber AG, Ho MN, O’Brien MJ, Gottlieb LS, Sternberg SS, Waye JD, Schapiro M, Bond JH, Panish JF (1993) Prevention of colorectal cancer by colonoscopic polypectomy. The National Polyp Study Workgroup. N Engl J Med 329: 1977-1981

Zhou HM, Nichols A, Meda P, Vassalli JD (2000) Urokinase-type plasminogen activator and its receptor synergize to promote pathogenic proteolysis. EMBO J 19: $4817-4826$ 